Short communication

\title{
A new and more precise experiment method for characterizing the mineralogical heterogeneity of unconventional hydrocarbon reservoirs
}

\author{
Shuheng Du ${ }^{\mathrm{a}, \mathrm{b}, \mathrm{c}}$, Shan Pang ${ }^{\mathrm{a}, \mathrm{c}}$, Yongmin Shi ${ }^{\mathrm{c}, *}$ \\ a School of Earth and Space Science, Peking University, Beijing 100871, China \\ ${ }^{\mathrm{b}}$ Institute of Mechanics, Chinese Academy of Sciences, Beijing 100190, China \\ c Oil and Gas Institute, Peking university, Beijing 100871, China
}

\section{A R T I C L E I N F O}

\section{Keywords:}

Unconventional hydrocarbon reservoirs

Mineralogical heterogeneity

Hydrocarbon exploitation

\begin{abstract}
A B S T R A C T
This study is aimed to introduce the new and more precise experiment method which could characterize the mineralogical heterogeneity of unconventional hydrocarbon reservoirs. As the $2 \mathrm{D}$ characterization methods and techniques still have a large amount of information to be excavated with quite strong vitality, the new method could be used to discover the minerals directly under the FE-SEM combining with the EDS method after considering both the resolution $(10 \mathrm{~nm})$ and representativeness $(20 \mathrm{~mm})$. The higher the ratio of the maximum to the minimum and the mean square deviation of each mineral parameter in thin sections from 8 different directions, the higher the microscopic heterogeneity of the reservoir. The new method would help to the study on enhancing the remaining unconventional hydrocarbon recovery.
\end{abstract}

\section{Background}

Unconventional reservoirs are usually characterised as quasi continuous or continuous accumulation, having a small pore-throat scale, strongly heterogeneous, and difficult to mine. The method to improve the characterisation of the heterogeneity of unconventional hydrocarbon reservoirs and their influence on exploitation has become an important scientific problem nowadays [1,2].

With the deepening of interdisciplinary research, high-resolution observation technology has been applied to the characterisation of unconventional reservoirs. Predecessors used micron computed tomography (CT), nano CT and focused ion bean-scanning electron microscopy (FIB-SEM) series technology to carry out much fruitful research work on unconventional reservoirs, and they obtained a series of important research conclusions [3-5]. However, with in-depth study and feedback from the practice, the technology has gradually exposed many core issues, such as a high cost, unreasonable CT threshold division and a poor representative sample size. In fact, resolution and representativeness are a pair of contradictions in reservoir characterisation that cannot be considered together nowadays [6,7]. Therefore, we should devise some innovative ideas to study the macroscopic and microcosmic characteristics of reservoir minerals and reservoir space on different scales, which could reduce the degree of the impact of the contradiction between resolution and representativeness to a certain extent [8-11].

The characterisation of mineralogical heterogeneity, especially of some brittle minerals, is significant in enhancing the recovery efficiency of unconventional hydrocarbon, because minerals influence the distribution characteristics of hydraulic fracturing. In addition, according to the principle of sedimentology, the formation of pore throats is essentially due to the accumulation, compaction and subsequent diagenesis of minerals, and this is achieved by the primary and secondary boundaries of minerals, where the boundaries of pore throats are the grain boundaries after denudation, transportation and reconstruction [12-14]. Pore-throat characteristics largely reflect the sorting and grinding properties of minerals, which is a true reflection of the deposition, compaction and modification processes. Hence, the formation of reservoir space and minerals during the deposition process has an obvious symbiotic relationship. In addition, the characteristics of minerals, especially brittle minerals, are rather important in reservoir stimulation and hydrocarbon exploitation [15-18].

Taking the unconventional sandstone reservoir for example, this paper introduces a new technique to characterise the mineralogical heterogeneity of reservoirs, quantitatively called 'umbrella deconstruction', which would also benefit further the innovation of other heterogeneity characterisations of unconventional reservoirs.

\footnotetext{
Abbreviations: CT, computed tomography; FE-SEM, field-emission-scanning electron microscope; EDS, energy dispersive spectrometer; 2D, two dimension; 3D, three dimension

* Corresponding author at: No. 5 Yiheyuan Road, Haidian District, Beijing, China.

E-mail address: sym@pku.edu.cn (Y. Shi).
} 


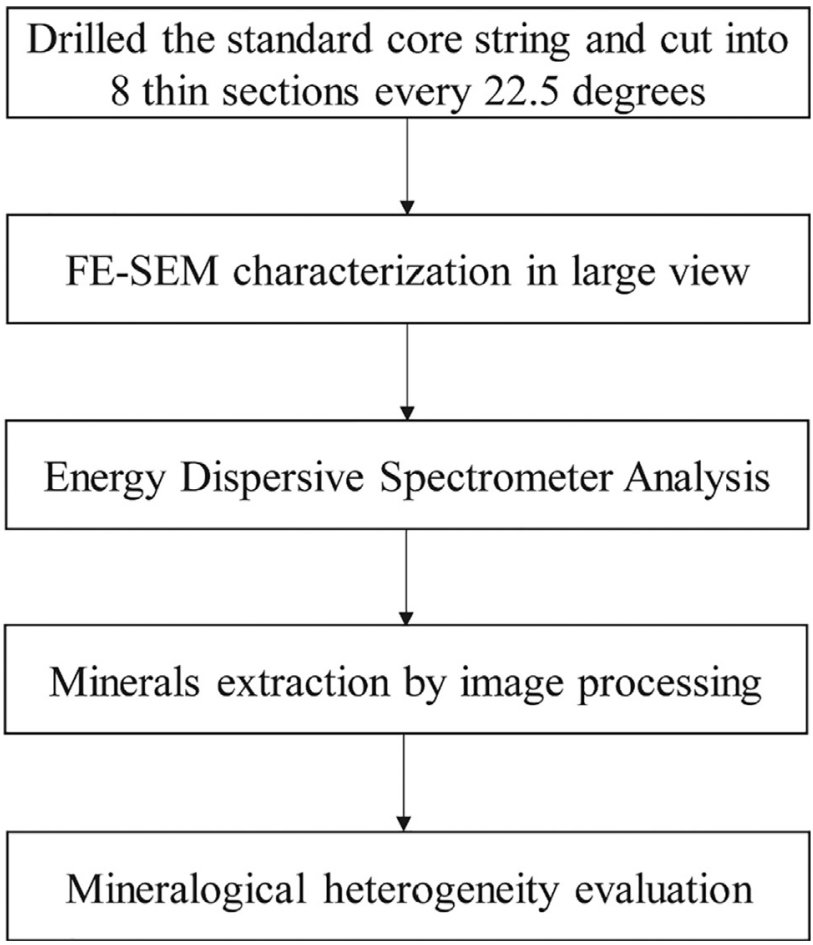

Fig. 1. Technical process of the new characterisation technique.

\section{Technical process}

According to the background analysis, the flowing chart of the technical process is shown in Fig. 1.

First, we drill the standard core sample with the diameter $(25 \mathrm{~mm})$ and length $(50 \mathrm{~mm})$, draw 8 lines every 22.5 degrees in the overlook surface of the sample and cut the thin sections along the 8 lines. Second, we carry out the FE-SEM characterization on the reservoir of 8 thin sections in large review. Third, the Energy Dispersive Spectrometer analysis should be carried out to identify the mineral type quantitatively. Fourth, we use the technology of image processing to extract the minerals respectively. Finally, we could carry out the parameter calculation of 8 thin sections to evaluate the mineralogical heterogeneity of the unconventional hydrocarbon reservoir.

The number of thin section could be adjusted according to our research purpose. But it is not the more sections, the better because we need to ensure that all the minerals in each thin section are independent of each other or it may cause paradox. When the number of slices is increasing, some mineral individuals will be destroyed for various reasons or even be divided into several parts. So the number of "eight" in this paper is based on the actual rock property and our research purpose which could meet the needs of the mineralogical heterogeneity characterization.

\section{Innovation discussion}

\subsection{Advantages of the new method}

Most of the research on the microscopic heterogeneity of reservoirs depends on the development of various testing techniques.

Micro or nano CT scanning has been widely used in the characterisation of unconventional reservoir space in recent years, and its importance and superiority are self-evident. Scholars proposed the maximum sphere method to carry out the segmentation of pore throats based on CT data $[19,20]$. Like other technologies, there are also some shortcomings in this technology. For example, resolution and representativeness cannot be taken into account at the same time, and the types of minerals cannot be judged carefully.

Field emission (FE)-SEM imaging could be effective in tight oil sandstone reservoirs based on the conductivity of minerals, and the accuracy could be up to $0.5 \mathrm{~nm}$. It can identify pore-throat spaces effectively, and the accuracy is much higher than that of casting thin sections. It is non-destructive to the reservoir sample. At the same time, the observation range is larger than the sample size and the analysis scale of nano CT, and it is also a little better than nuclear magnetic resonance because of the ease of operation and the low cost. Therefore, to achieve the purpose of accurately identifying pore throats, this study will identify a pore throat and the related minerals beside the pore throat effectively by combining with an energy spectrum analysis. The umbrella deconstruction method was put forth based on the combination of the FE-SEM method and other technology with the above advantages. The imaging observation scale could reach approximately

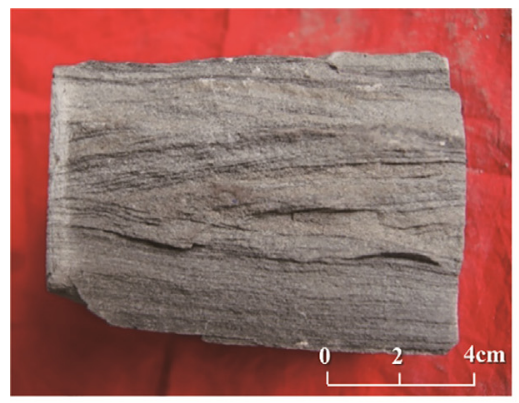

\begin{tabular}{cc}
\hline Properties & Descriptions \\
\hline Well & H191 \\
Porosity $\%$ & 6.6 \\
Permeability $/ 10^{-3} \mu \mathrm{m}^{2}$ & 0.05 \\
Phenomenon & $\begin{array}{c}\text { Wedge-shaped } \\
\text { cross bedding }\end{array}$ \\
\hline Properties & Descriptions \\
\hline Well & H198 \\
Porosity $/ \%$ & 11.0 \\
Permeability/10-3 $\mu \mathrm{m}^{2}$ & 0.51 \\
Phenomenon & $\begin{array}{c}\text { Strip distribution } \\
\text { of crude oil }\end{array}$ \\
\hline
\end{tabular}

Fig. 2. Typical rock samples observation and the basic information descriptions. 

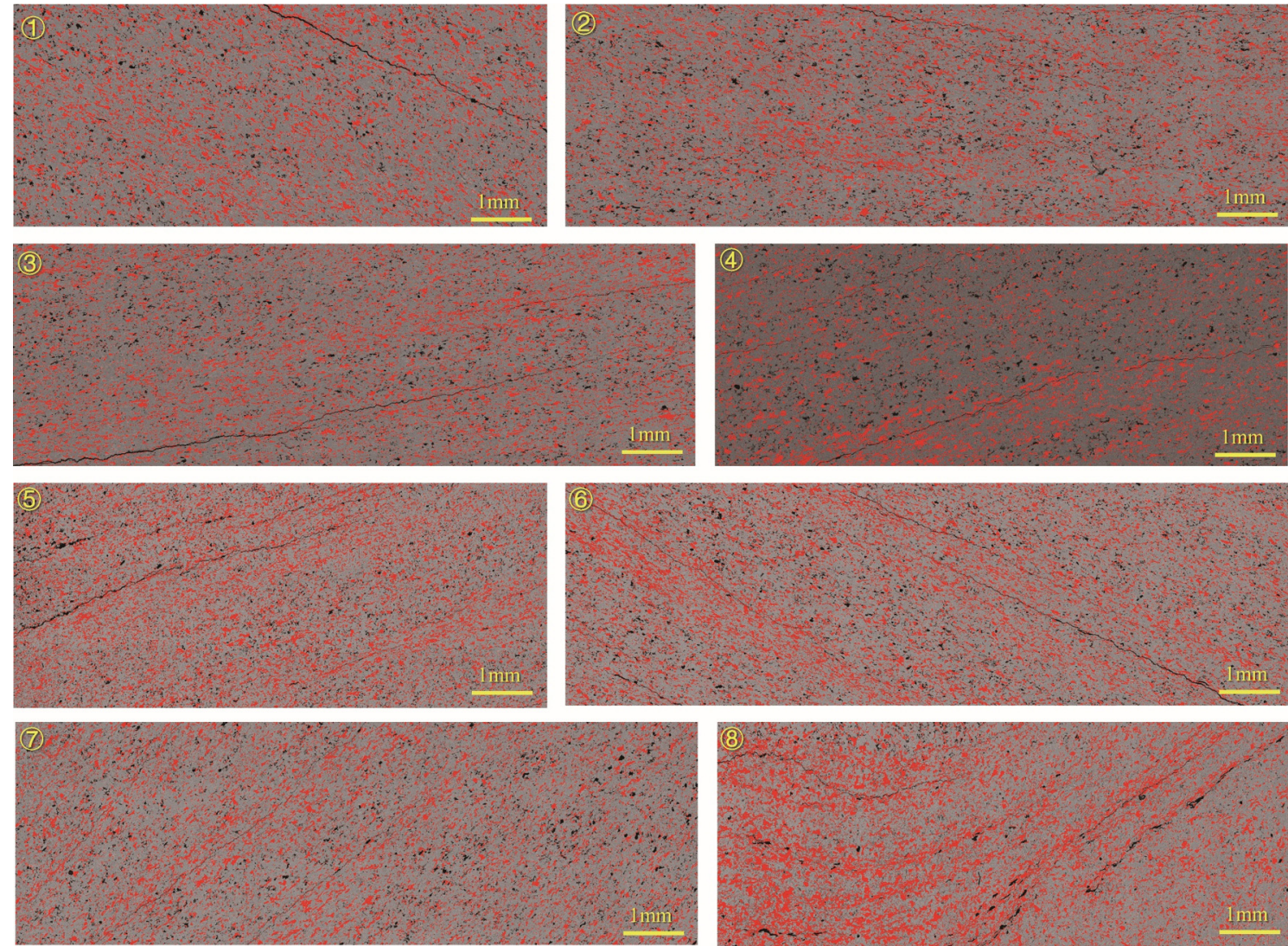

Fig. 3. FE-SEM Observation of the eight sections using the new method.
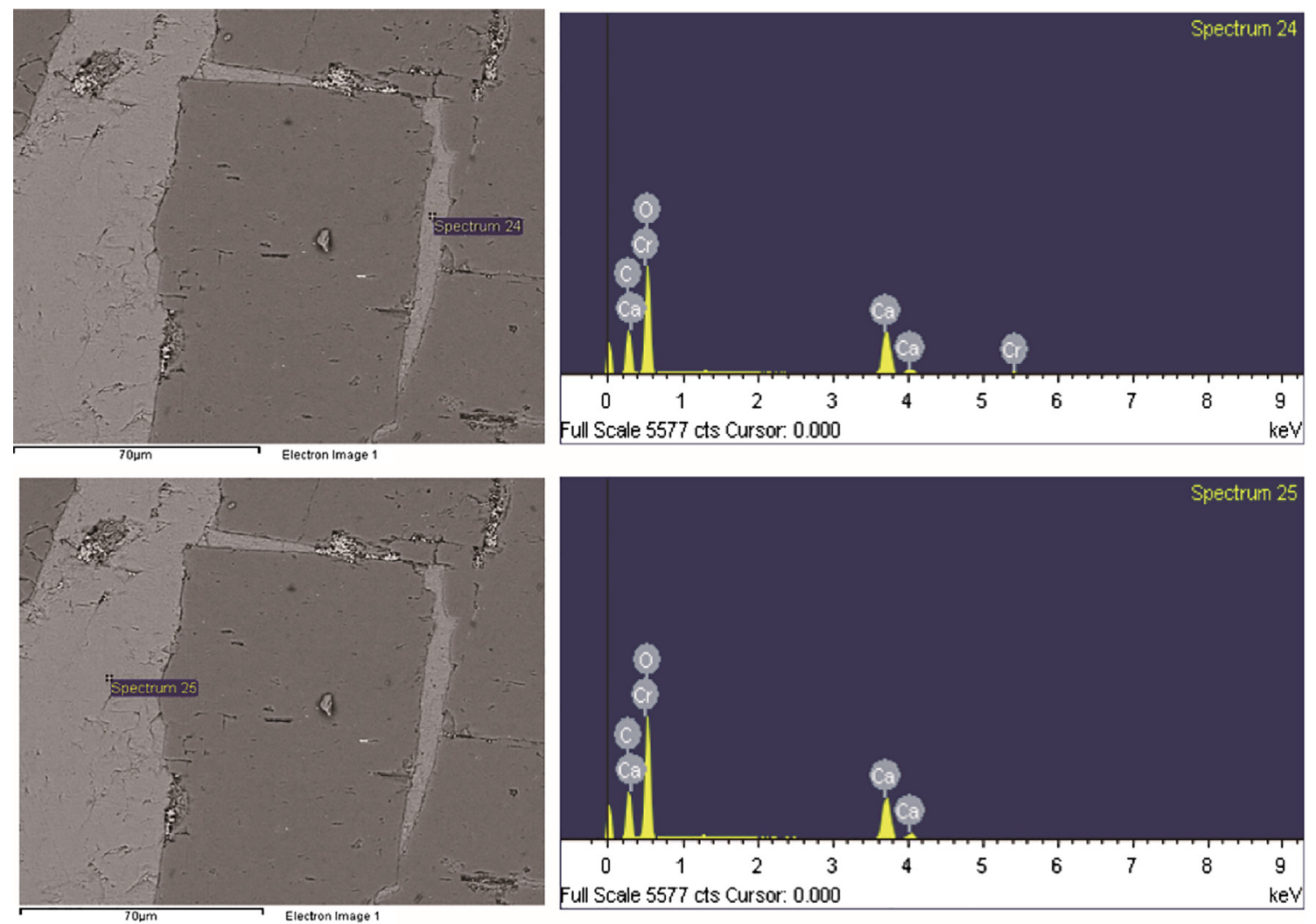

Fig. 4. EDS Analysis on the mineral type of fillings in the unconventional sandstone reservoir. 


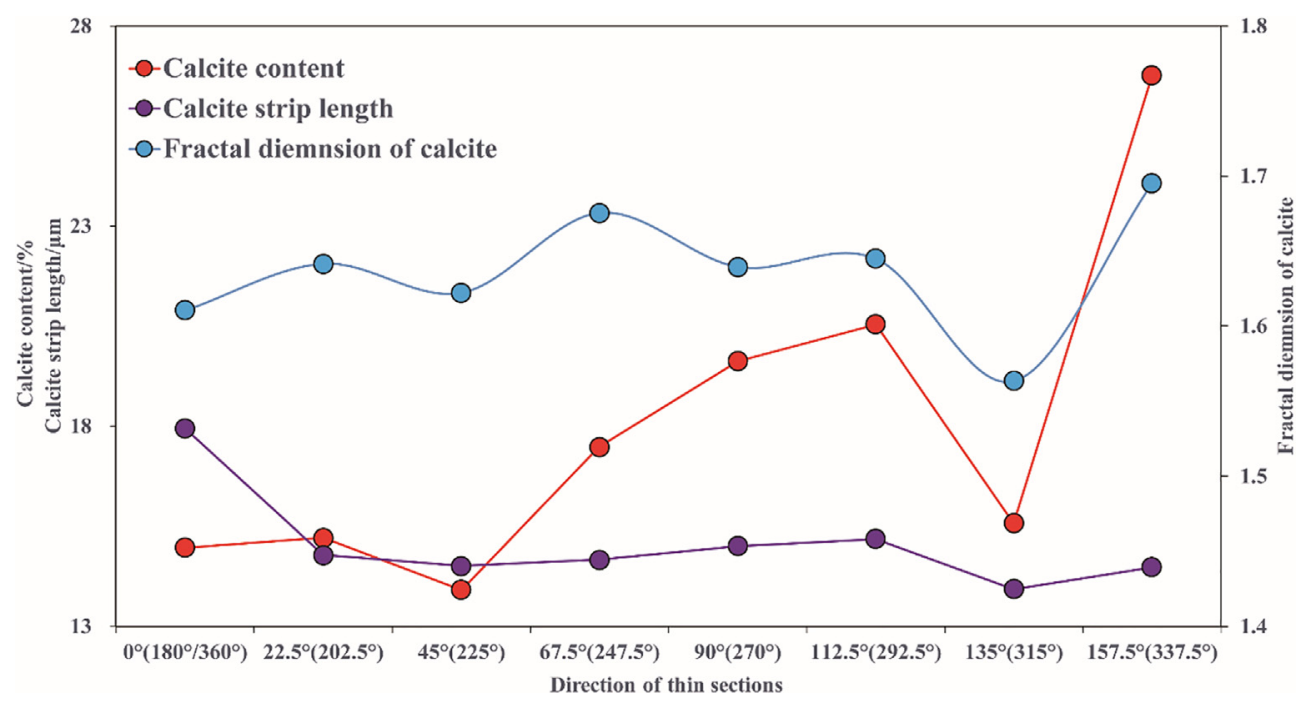

Fig. 5. The fractal dimension, calcite content and calcite strip length of the calcite calculation of the 8 thin sections.

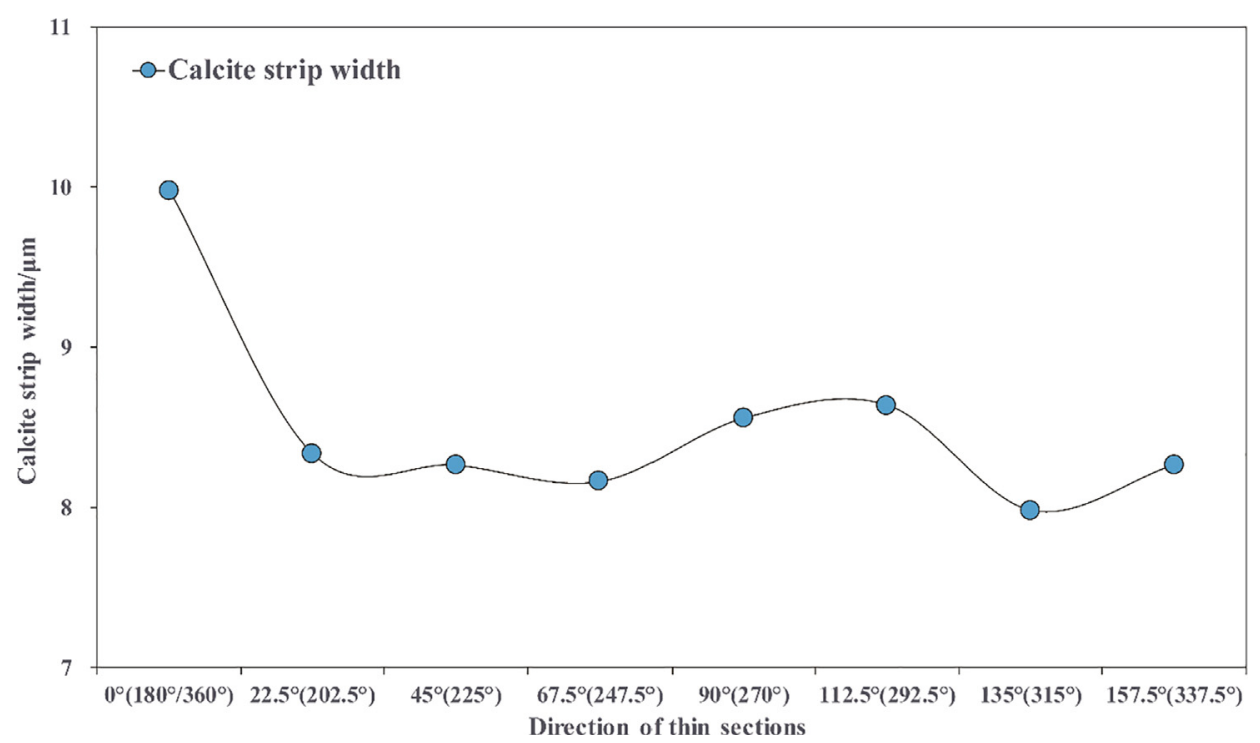

Fig. 6. The average calcite strip width of the calcite calculation of the 8 thin sections.

$20 \mathrm{~mm}$ (10 times the CT observation scale), and the final precision could reach about $10 \mathrm{~nm}$.

In addition, we could discover the minerals directly under FE-SEM combined with the energy dispersive spectrometer (EDS) method, but the CT method alone could not be effective.

\subsection{Feasibility, potential replication and limitation}

With the introduction of 3D reservoir testing technology, such as CT and FIB-SEM, the original technology for reservoir characterisation based on 2D technology has been affected, but it still cannot be ignored, which means the 2D characterisation methods and techniques still have a large amount of information to be excavated with quite strong vitality $[21,22]$.

(1) It is necessary to point out that the study of the characterisation of unconventional hydrocarbon reservoirs should focus on the ultimate goal, which is improving oil recovery and clarifying the occurrence position and flow mechanism of oil and gas. Therefore, we should not blindly pursue the 3D characterisation when we have not excavated the 2D information completely. The author believes that nowadays, we still cannot figure out the key technologies, such as the high-precision scanning, storage, statistics and analysis of massive reservoir data and improving CT resolution and scanning scales to solve the contradiction between representation and resolution in a short time, but $2 \mathrm{D}$ characterisation still has great potential in research. Therefore, besides the 3D testing and characterisation technology, we can still not relax full attention on the 2D information. In addition, with the development of wide field imaging technology, the contradiction between resolution and representation will first be resolved in the $2 \mathrm{D}$ space. Therefore, we cannot blindly abandon the 2D characterisation method and neglect the importance of $2 \mathrm{D}$ technology to mineral recognition and characterisation. The identification of pore throats and minerals and the discovery of ultra-nano pores in shale gas reservoirs are both based on the observation and characterisation of cast thin sections or FESEM in 2D space.

(2) Stereology theory shows that the feature points in 3D space can be characterised by the feature points in the $2 \mathrm{D}$ space. This is also the core theoretical basis for a previous significant breakthrough in reservoir space in 2D space, which has been proven by engineering practice. Of course, this does not ignore the important role of 3D test technology in the field of unconventional hydrocarbon reservoir development. On the contrary, we should emphasise that 
Table 1

Comprehensive scope of characteristics to be considered of the new method.

\begin{tabular}{|c|c|c|c|}
\hline $\begin{array}{l}\text { Research } \\
\text { objectives }\end{array}$ & $\begin{array}{l}\text { Characterisation } \\
\text { parameters }\end{array}$ & Advantages & Limitations \\
\hline $\begin{array}{l}\text { Mineralogical } \\
\text { heterogeneity }\end{array}$ & $\begin{array}{l}\text { Mineral content } \\
\text { Mineral particles } \\
\text { Size } \\
\text { Mineral particle } \\
\text { shape } \\
\text { Mineral } \\
\text { orientation } \\
\text { Combination of } \\
\text { mineral types }\end{array}$ & $\begin{array}{l}\text { The new method } \\
\text { could get the } \\
\text { visualized and } \\
\text { quantitative } \\
\text { conclusion on the } \\
\text { microscopic } \\
\text { heterogeneity of } \\
\text { minerals, pores and } \\
\text { fractures }\end{array}$ & $\begin{array}{l}\text { The precision of } \\
\text { mineral } \\
\text { recognition could } \\
\text { get the further } \\
\text { improvement }\end{array}$ \\
\hline $\begin{array}{l}\text { Pore } \\
\qquad \text { heterogeneity } \\
\text { in matrix }\end{array}$ & $\begin{array}{l}\text { Matrix porosity } \\
\text { Pore type and } \\
\text { structure } \\
\text { Pore radius } \\
\text { distribution } \\
\text { Pore shape } \\
\text { Pore orientation } \\
\text { Combination of } \\
\text { pore types }\end{array}$ & & $\begin{array}{l}\text { The identification } \\
\text { of pore boundary } \\
\text { could get the } \\
\text { further } \\
\text { improvement }\end{array}$ \\
\hline $\begin{array}{l}\text { Fractures } \\
\text { heterogeneity }\end{array}$ & $\begin{array}{l}\text { Fracture porosity } \\
\text { Fracture type } \\
\text { Fracture length } \\
\text { Fracture width } \\
\text { Fracture } \\
\text { orientation }\end{array}$ & & $\begin{array}{l}\text { The identification } \\
\text { between the } \\
\text { artificial and } \\
\text { natural fractures } \\
\text { could be taken } \\
\text { into further study }\end{array}$ \\
\hline
\end{tabular}

while we want to introduce new technologies to the reservoir research, at the same time, if we can closely focus on the purpose of our study and continue to discover other significant information fully using existing technology, it could also be regarded as a material and information fusion.

Similarly, the umbrella deconstruction method was put forth based on the $2 \mathrm{D}$ characterisation technology, which has the above feasibility and potential replication.

\section{Application}

Take the unconventional sandstone reservoir for example, where typical rock sample pictures and basic information descriptions are listed in Fig. 2. We drilled the standard core string and cut into eight thin sections every 22.5 degrees. FE-SEM observation of the eight thin sections was carried out, and the results are shown in Fig. 3. The red parts in Fig. 3 indicate the fillings components. To identify the mineral types of the fillings, the EDS analysis was carried out. The results show (Fig. 4) that the calcite is the main component of the fillings and of the typical brittle mineral, which is of great significance for hydraulic fracturing to form effective seepage channels. Therefore, the calcite strip was taken as the main object to characterise in this study because of its significance in reservoir stimulation. The microscopic heterogeneity of other types of minerals could also be studied like the calcite.

As we know, the mineral content can represent the overall degree of mineral development. The fractal dimension would be a good parameter to characterise the complexity of mineral development. The average length and width of the calcite strip can reflect the potential of reservoir stimulation. Therefore, the above four kinds of representative mineral attribute parameters would be calculated. The change curves of the above parameters of eight sections could be drawn (Figs. 5 and 6) and the microscopic heterogeneity is observed.

Taking the unconventional sandstone reservoir in Fig. 2 for example, results in Figs. 5 and 6 show that the minimum length and width of the calcite strip appeared in the direction of 135 degrees (315 degrees). Meanwhile, the fractal dimension of the calcite in this direction is the lowest, and the calcite content is also one of the lowest. It can be preliminarily judged that the fracture of the reservoir in the direction of
135 degrees (315 degrees) would be the largest scale, and the potential of the stimulation would also be greatest, which means the remaining oil has the greatest potential for mining.

As for the microscopic heterogeneity evaluation, the higher the ratio of the maximum to the minimum and the mean square deviation of each mineral parameter in the eight thin sections, the higher the microscopic heterogeneity of the reservoir.

Regarding other evaluation parameters, such as the similar properties in pores and fractures, we could also generate another significant conclusion that would help enhance hydrocarbon recovery. The comprehensive scope of characteristics to be considered regarding the new method is shown in Table 1.

\section{Conclusion}

The umbrella deconstruction method was put forth based on a combination of the FE-SEM method and other technology with the above advantages. The imaging observation scale could reach approximately $20 \mathrm{~mm}$ (10 times the CT observation scale), and the final precision can reach about $10 \mathrm{~nm}$. In addition, we could discover the minerals directly under the optical microscope, which could allow for the recognition of minerals by combining with the EDS method, but the CT method could not be effective.

As a method for characterising mineralogical heterogeneity after considering both resolution and representativeness is not technically available, the umbrella deconstruction method would be a more precise and effective method in 2D space to study the microscopic heterogeneity of unconventional hydrocarbon reservoirs.

Meanwhile, the method of characterising microscopic heterogeneity is one of the most important research hotspots that needs to be further explored. It will play an important role in improving unconventional hydrocarbon recovery.

\section{Acknowledgements}

This work is Granted by Chinese national project of science and technology research (No. 2017ZX05013005-009). Thank Professor Ping Guan and my dear friend Xiaoli Gao for the support to this work.

\section{References}

[1] Zhao Y, Sun Y, Liu S, Chen Z, Yuan L. Pore structure characterization of coal by synchrotron radiation nano-CT. Fuel 2018:215:102-10.

[2] Tiwari P, Deo M, Lin CL, Miller JD. Characterization of oil shale pore structure before and after pyrolysis by using X-ray micro CT. Fuel 2013;107:547-54.

[3] Dai S, Liu J, Ward CR, et al. Petrological, geochemical, and mineralogical compositions of the low-Ge coals from the Shengli Coalfield, China: a comparative study with Ge-rich coals and a formation model for coal-hosted Ge ore deposit. Ore Geol Rev 2015;71:318-49.

[4] Desbois Guillaume, Urai Janos L, Hemes Susanne. Multi-scale analysis of porosity in diagenetically altered reservoir sandstone from the Permian Rotliegend (Germany). J Pet Sci Eng 2016;140:128-48.

[5] Berrezueta Edgar, Kovacs Timea. Application of optical image analysis to the assessment of pore space evolution after $\mathrm{CO} 2$ injection in sandstones. A case study. J Pet Sci Eng 2017;159:679-90.

[6] Rees Emily VL, Priest Jeffery A, Clayton Chris RI. The structure of methane gas hydrate bearing sediments from the Krishna-Godavari Basin as seen from Micro-CT scanning. Mar Pet Geol 2011;28:1283-93.

[7] Ge XM, Fan YR, Li JT, et al. Pore structure characterization and classification using multifractal theory - an application in Santanghu basin of western China. J Petrol Sci Eng 2015;127:297-304.

[8] Baniak Greg M, Gingras Murray K, George Pemberton S. Reservoir characterization of burrow-associated dolomites in the Upper Devonian Wabamun Group, Pine Creek gas field, central Alberta, Canada. Mar Pet Geol 2013;48:275-92.

[9] Huang WB, Lu S, Osman Salad Hersi F, et al. Reservoir spaces in tight sandstones: classification, fractal characters, and heterogeneity. J Nat Gas Sci Eng 2017; 46:80-92.

[10] Busse J, de Dreuzy JR, Galindo Torres S, et al. Image processing based characterization of coal cleat networks. Int J Coal Geol 2017;169:1-21.

[11] Dorador Javier, Rodríguez-Tovar Francisco J. Digital image treatment applied to ichnological analysis of marine core sediments. Facies 2014;60:39-44.

[12] Liu Kouqi, Ostadhassan Mehdi, Zou J, et al. Multifractal analysis of gas adsorption isotherms for pore structure characterization of the Bakken Shale. Fuel 
2018;219:296-311.

[13] London M, Cameron SM, Donald J, Wassmuth FR. Water-flooding experiments with X-ray CT imaging. Society of Petroleum Engineers; 2014.

[14] Josh M, Esteban L, Delle Piane C, et al. Laboratory characterization of shale properties. J Petrol Sci Eng 2012;88:107-24.

[15] Tiwari P, Deo M, Lin CL, et al. Characterization of oil shale pore structure before and after pyrolysis by using X-ray micro CT. Fuel 2013;107:547-54.

[16] Peng RD, Yang YC, Ju Y, et al. Computation of fractal dimension of rock pores based on gray CT images. Chin Sci Bull 2011;56:3346.

[17] Salem AM, Ketzer JM, Morad S, Rizk RR, et al. Diagenesis and reservoir-quality evolution of incised-valley sandstones: evidence from the Abu Madi Gas Reservoirs (Upper Miocene), the Nile Delta Basin. Egypt J Sediment Res 2005;75:572-84.

[18] Mayo Sheridan, Josh Matthew, Nesterets Yakov. Quantitative micro-porosity characterization using synchrotron micro-CT and xenon K-edge subtraction in sandstones, carbonates, shales and coal. Fuel 2015;154:167-73.

[19] Dong H. Micro-CT imaging and pore network extraction. London: Imperial College; 2007.

[20] Silin DB, Jin G, Patzek TW. Robust determination of pore space morphology in sedimentary rocks. SPE 842962003.

[21] Song WH, Yao J, Ma JS, et al. Pore-scale numerical investigation into the impacts of the spatial and pore-size distributions of organic matter on shale gas flow and their implications on multiscale characterization. Fuel 2018;216:707-21.

[22] Ju W, Shen J, Qin Y, et al. In-situ stress state in the Linxing region, eastern Ordos Basin, China: implications for unconventional gas exploration and production. Mar Pet Geol 2017;86:66-78. 